\section{K. Kgwete}

Irma Eloff is acting dean of education and Head of Education Psychology, University of Pretoria, South Africa. L. K. Kgwete works in Student Support Services, University of Pretoria.

\section{South African Teachers'} Voices on Support in Inclusive Education

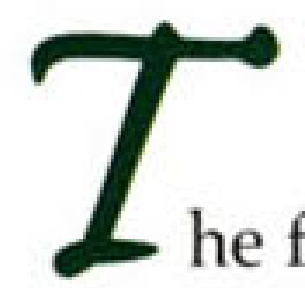

he formation of a democratic government brought significant changes in South Africa. Today, the majority of education services are decentralized, and so the provinces have taken on the responsibility of implementing national education policies and plans. South Africa has 12 million children in school and approximately 366,000 teachers in approximately 28,000 schools, including 390 schools for children with special needs and 1,000 registered private schools. Of those schools, 6,000 are high schools (grade 7 to grade 12) and the rest are primary (grade 1 to grade 6) (Garson, 2006). Children attend school for 12 years, in addition to the first year (called grade 0). Grades 10, 11, and 12 are not compulsory; however, they are required prior to tertiary education. A relatively large portion of the annual budget is dedicated to education. In 2006, approximately $\$ 417.9$ billion was slated for education, which amounted to 24 percent of non-interest expenditures (Garson, 2006).

Teachers in South Africa deal with the remnants of an inherited education system based on segregation and exclusion of particular groups of students. While the previous practices of segregation resided within the context of racial groupings, exclusionary practices related to disabilities, academic abilities, and language competence are evident today. Even though the lines of exclusion are more permeable today, the conceptual underpinnings that sustain segregation have a residual effect on support for inclusive education and subsequently on quality of teacher support.

\title{
Inclusive Education in South Africa
}

The introduction of inclusive education in South Africa was a direct response to Act 108 of 1996 and also a national commitment to the Education for All movement, as stated in the UNESCO Salamanca Statement (1994). The worldwide move towards inclusion also formed a fortunate parallel with the transition towards a fair and
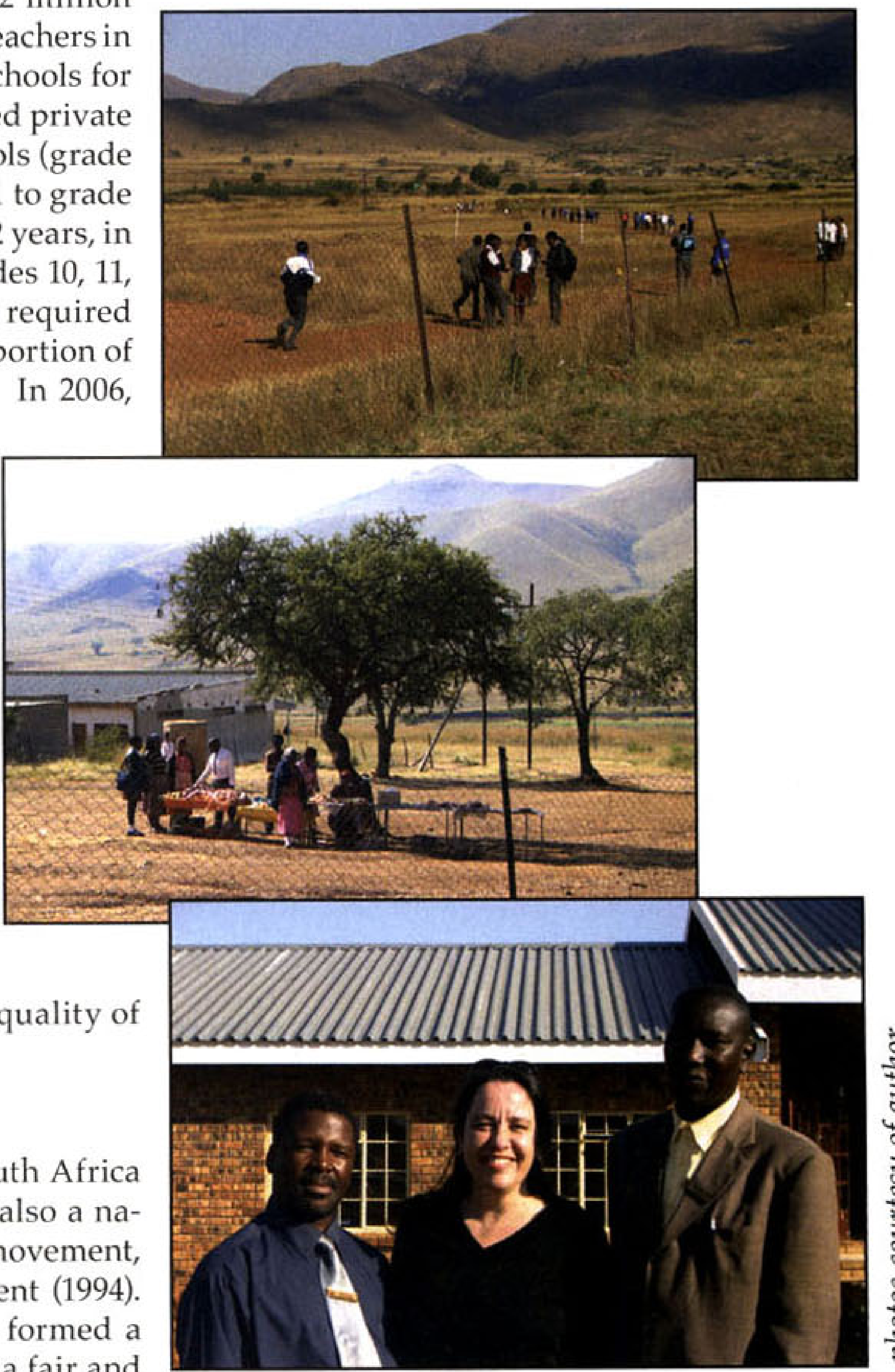
just South Africa. The first free, democratic South African elections that took place in 1994 coincided with the global proliferation of declarations on Education for All, as well as with conceptual shifts in providing access to education for all children. This convergence shaped opportunities for raising awareness, creating widespread support for inclusion, and easing the implementation of pilot projects in South Africa.

Education White Paper 6 (Department of National Education, 2001) is the guiding document for the implementation of inclusive education in South Africa. It began as a standing policy. All nine provinces conducted awareness campaigns to educate and prepare communities for inclusive education; in addition, workshops and trainings were organized to prepare all stakeholders for incorporating this policy. First, the National Department of Education prepared the Draft Guidelines for the Implementation of Inclusive Education and made them available in all nine provinces, and then schools were selected in each province to start a national pilot project. The provincial governments also were mandated to provide continuous support in policy implementation in the selected schools. Teachers and officials received training before the implementation.

According to Education White Paper 6 (Department of National Education, 2001), the apartheid government had established about 380 special schools. Special needs education today includes the provision of education to children with special needs within mainstream education. Furthermore, the term "special needs" includes such systemic factors as poverty, health problems, nutrition, street children, and children affected by the impact of HIV/AIDS. Data indicate that out of approximately 400,000 children with disabilities in the country, only 64,200 were accommodated in these schools. The Department of National Education (2001) also indicates that the provision of special education is costly because it demands a low learner-educator ratio, highly trained staff, and specialized teaching material and equipment. In addition, the establishment of separate schools for children with special needs also creates geographical accessibility problems. Learners with various disabilities are spread throughout the country, while dedicated special schools exist in some regions. Further, services and resources in these schools are not evenly distributed, with former white and urban schools being relatively well-resourced. Creating an inclusive school environment where students of different races, different abilities, and both genders could interact became a priority.

Mainstream educators have to contend with large class sizes (e.g., 50-80 children in some classrooms), limited educational resources, language diversity, and the dire effects of HIV/AIDS on families, teachers, and the children themselves. Teachers must find ways to include children with disabilities in mainstream classrooms, despite these systemic constraints. While the values of inclusive education are embraced in light of a progressive constitution (Republic of South Africa, 1996), the pragmatic questions often trump the principle of inclusion. How do we include children with disabilities within these constraints? How can we support teachers to become effective in inclusive settings?

\section{Support for Teachers in Inclusive Settings: What Does Research Suggest?}

In South Africa, it is imperative to think about different ways to support teachers in coping with the challenges of an inclusive classroom. Research suggests various teacher supports. Boyer and Gillespie (2000) mention that some countries have addressed the issue of support through task forces, long-term studies, short-term professional development, and even shorter-term pay incentives. Arbeiter and Hartley (2002) suggest that the support that teachers need includes appropriate training (i.e., preservice and inservice), as well as community and parental involvement. According to Frank (1999), a paradigm shift is required to move away from a "firefighting model" toward a long-term approach that is proactive, effective, and financially sound. South Africa's White Paper 6 on Special Needs Education (Department of National Education, 2001) points out strengthened school-based supportservices and district support teams made up of staff from provincial districts.

Support in inclusive education is a complex and multilayered phenomenon. Although substantial research on inclusive education has been done in South Africa, limited research has focused on teacher support. The study conducted by Lomofsky and Lazarus (2001) examined the first steps in the development of an inclusive education system in South Africa. The majority of teachers surveyed in one study (Hay, Smit, \& Paulsen, 2001) felt unprepared and unequipped for working in inclusive classrooms. Bothma, Gravett, and Swart (2000) found that South African primary school teachers' attitudes toward inclusive education were negative, thereby creating a critical barrier to its successful implementation. Furthermore, some studies on inclusive education in South Africa raise concerns about implementing inclusion without concomitant strategies for teacher support. A study by Eloff, Swart, and Engelbrecht (2002) indicated that the inclusion of a child with a physical disability led to relatively little stress for teachers, while the comparative study on the inclusion of a child with a cognitive disability provides evidence of increased stress levels for teachers (Engelbrecht, Oswald, Swart, \& Eloff, 2003). To date, studies on inclusion have focused strongly on different role players in inclusive education (Gugushe, 1999; Hyam, 
2002; Kriel, 2001; Swart, Engelbrecht, Eloff, Oswald, \& Pettipher, 2004). However, teacher support for successful inclusion needs to be examined.

\section{What Do Teachers Perceive as the Key Areas for Support for Inclusive Education?}

In light of the challenges faced by teachers in South Africa, the authors explored the key areas for support in inclusive education among teachers in the Gert Sibande Region (which falls under the Mpumalanga Education Department). The region has a total of 964 schools, of which 85 percent are situated in rural areas. Some of these schools are situated on farms, with very few children attending. Out of the 964 schools, 50 have been identified by the provincial government as pilot schools for inclusive education. There are two inclusive education projects sponsored by nongovernmental organizations (NGOs). One project is sponsored by the Finnish government (i.e., The SCOPE Project; South African-Finnish Co-operation in the Education Sector), and the other is sponsored by the Canadian government. Currently, only three schools are involved in each project.

In addition to providing training on inclusive education for principals, school governing bodies, and educators in the pilot schools, the provincial government organized awareness campaigns for communities where the pilot schools are located. The community and other stakeholders were made aware of the changes in the education system through such activities as presentations, plays, and poetry sessions that introduce the concept of an inclusive education system. Parents also are encouraged to enroll children with special needs in these pilot schools. Training (in the form of workshops and inservice) is provided to teachers to help them better understand inclusive education and to empower them with skills that will help them meet students' diverse needs. In addition, volunteers (such as retired remedial teachers, nurses, and parents) provide support services in these schools. Other government departments are also involved in the pilot schools to provide necessary services.

Teachers were observed and interviewed to explore their views about support while performing their daily duties at school. The school where the observation and interviews were conducted was one of the 12 schools chosen by the National Department of Education to pilot inclusive education in the Mpumalanga Province. Located in a rural area, the school served 692 students (Grade 1 - Grade 7), with 19 educators and a principal. The participants included teachers, the principal, and support personnel in the Gert Sibande region. Classroom observations were conducted during school visits and 12 educators and one support personnel member were interviewed. Participation was optional. The authors recorded their observations on paper during and after classroom presentations, teachers' meetings, and on the school playground. Notes taken during observation were kept in a file.

Teachers' ages ranged between 32 and 55 . The level of qualifications varied from a three-year education diploma to an honors degree in education. Four of the teachers interviewed were involved in Foundation Phase classes, three were in the Intermediate Phase, and four teachers and the principal were in theSenior Phase. Five teachers were males and seven were females. All teachers in the school received inservice training on inclusive education. The educators received ongoing support, in the form of workshops and mentoring activities provided by inclusive education officials from the district, in the area of accommodating children with various disabilities. The support personnel member who was interviewed was an occupational therapist. She visited the school once a week to support both students and educators.

The following themes, with regard to teachers' perspectives on support for inclusive education, were identified: 1) perceived lack of skills and competence, 2) large classes, and 3) insufficient resources.

Perceived Lack of Skills and Competence. Teachers indicated a lack of skills and competence to accommodate diversity in inclusive classrooms as one of their main challenges and, therefore, an area in which teacher support can be crucial. They indicated that they did not have the necessary skills and competencies to handle students experiencing barriers to learning in their classrooms. They all believed that they were failing to meet the needs of all students, due to their limited skills. This finding was also confirmed by the researchers' observations during visits in the classrooms.

Most teachers mentioned that they had not received any formal training on addressing students' needs in an inclusive classroom. These teachers had obtained ordinary ("mainstream") diplomas and degrees in education. They indicated that they felt unprepared to help the students, because their preservice training did not focus on assisting students with diverse needs. The teachers also indicated that the inservice training they received in preparation for inclusive education was too brief-mainly conducted in the afternoon after a long school day.

Lack of skills and competence (or, in this case, the perception of lack of skills and competence) has been mentioned in several studies on inclusion in South Africa (Engelbrecht, Forlin, Eloff, \& Swart, 2001; Hay, Smit, \& Paulsen, 2001). While some studies (Engelbrecht \& Forlin, 1998; Swart, Engelbrecht, Eloff, \& Pettipher, 2001) have indicated that the attitude of a 
teacher is a more important predictor of successful inclusion than the teacher's training, the consistency with which this issue is raised across studies in South Africa illustrates the need for further exploration.

Large Classes. The teachers mentioned that a high number of students in the classroom made it difficult for them to adequately teach in inclusive classrooms. They indicated that their department heads expected them to complete a specified volume of work within a given time period while simultaneously assisting students who are experiencing barriers to learning. Further, the teachers indicated that they experienced difficulties in giving individual attention to students with slower work tempos while managing their classrooms. Large classes ( 50 students or more) are endemic to rural schools in South Africa. Schools in rural areas are often understaffed and under-resourced; subsequently, teachers feel hard-pressed to provide the necessary support for all the children in their classrooms. Thus, children with special needs often are construed by teachers as an additional stressor.

Insufficient Resources. Teachers indicated insufficient human resources as one of the challenges of inclusive education, as well as one of the main starting points for support for teachers in inclusive education. They mentioned that the small number of teachers and support staff in the school interfered with the provision of quality education in the inclusive school. Similarly, the participants pointed to a need to employ more teachers in the school, as their workload left them overly burdened. The participants also mentioned that the school does not have sufficient support personnel, and does not have full-time access to the district support team, as they are also understaffed. The teachers expressed a need for administrative staff, teacher assistants, and general helpers in their classrooms. Further, the participants lamented the lack of material resources, such as teaching aids, student transport, and physical structures that can support inclusivity.

The participants also described challenges regarding student transport. They mentioned that most students lived far away from the school. According to the participants, the majority of students with physical barriers traveled long distances to the school with their wheelchairs. In addition, they mentioned that the school's poor physical facilities (bathroom, classrooms, and sports fields) often prevented successful implementation of inclusive education programs.

Since the country's first indigenous policy documents on education for all were published (DoE, 1997), research has highlighted the lack of resources for supporting children with special needs and for the teachers. Poverty has played a role on multiple levels, perhaps most of all on the provision of educational support for the poorest of the poor.

\section{After the Interviews and Observations}

It has become evident that teachers can feel challenged by the introduction of inclusive education in their school. The interviews and observations in the Gert Sibande region may help identify key areas where participating teachers perceive they need the most support.

It is significant that the participants in the interviews and observation emphasized their own (perceived) lack of skills and competence in dealing with diversity as a key area for support. They assumed that they are not dealing with the diversity in their classrooms, especially with the diversity that the students with disabilities bring to their classrooms, and they claimed a lack of skills and competence related to this diversity. The participants mostly negated their own expertise and also remained silent about the benefits and inherent expertise of collaborative relationships that have been present since the introduction of inclusive education at their school.

The participants ignored the distinctions between broad education challenges, such as large classes, and the challenges of inclusive education. This blurred distinction has consequences. For instance, they viewed large classes as a challenge in inclusive education, and then drew direct inferences in terms of time constraints and the inability to provide individual assistance to students in large classrooms. They did not recognize that inclusive education can bring relief in terms of time pressure, and that individual assistance is not a key aspect of inclusive education. They also did not recognize that large classes are not a distinct challenge for inclusive education, but rather a major educational challenge in South Africa.

The participants framed inclusive education solely in terms of students with disabilities. They equate inclusive education with the presence of a student with a disability in the classroom. They refer to "physically disabled students," "blind students," and "the deaf," and they do not define inclusive education as education for all students, but rather as "special education" within their classrooms.

Furthermore, they defined diversity in terms of ability and disability, yet classrooms usually include diversity factors with a much stronger impact on learning ability than disability (e.g., poverty, trauma, health). Whereas every classroom has a diversity of students, the participants in this study primarily viewed diversity in terms of students with disabilities.

Tension remains about the availability of resources for inclusive education. Participants mentioned a need for human as well as material resources to such an extent that this emerged as a key theme 
from the interview data. Insufficient resources, they said, was a challenging factor in the inclusive school. Yet some participants also mentioned the significant contributions made by NGOs and the government, as well as help from such resources as Braille machines, computers, toys, and textbooks provided by a SCOPE Project. Some also mentioned that an annual grant from the government allowed the school to purchase the material resources needed. While resources are available, the findings suggest that more are needed.

\section{Conclusion}

Although complex, the identified themes among teachers and principals at this specific school in the Gert Sibande region of South Africa explore the areas in which teachers need support for inclusive education. Even though the study is high on context specificity, some of the themes may resonate with teachers elsewhere. We believe that the identified challenges and themes can serve as departure points for the implementation of support programs for teachers in inclusive education settings globally.

This group of teachers from a rural school in South Africa focused on a perceived lack of skills and training, large classes, and lack of resources. Does this mean that, should these conditions be alleviated, teacher support for inclusive education would be sufficient? Probably not. However, it does mean that sufficient training, reasonable classroom sizes, and adequate provision of resources for inclusion (e.g., as measured by number of teachers, support staff, and material resources) need to be in place for teachers to feel that they are empowered and supported for inclusive education. The necessary policies for supporting inclusion are in place, and the constitution of South Africa provides the foundation upon which inclusion can be propagated and developed. In the classroom, however, teachers need to be provided with tangible support. We believe that this is applicable to all teachers who are welcoming a child with a disability in their classrooms. However, we also believe that this support should be conceptualized broadly-as teacher support for the inclusion of all children, and not only for those teachers who are teaching a child with a disability.

\section{References}

Arbeiter, S., \& Hartley, S. (2002). Teachers' and pupils' experiences of integrated education in Uganda. International Journal of Disability, Development and Education, 49, 61-68.

Bothma, M., Gravett, S., \& Swart, E. (2000). The attitudes of primary school teachers towards inclusive education. South African Journal of Education, 20, 200-204.

Boyer, L., \& Gillespie, P. (2000). Keeping the committed:
The importance of induction and support for new special educators. Teaching Exceptional Children, 33, 10-15.

Constitution of the Republic of South Africa. (1996). Act 108.

Department of National Education (DNE). (2001). Education White Paper 6 on special needs education. Building an inclusive education system. Pretoria: Government Printers.

Eloff, I., Swart, E., \& Engelbrecht, P. (2002). Including learners with physical disabilities: Stressful for teachers? Koers, 67, 77-99.

Engelbrecht, P., \& Forlin, C. (1998). Pre-service teachers' acceptance of and interactions with people with disabilities: The South African scene. African Journal of Special Needs Education, 3(1), 1-10.

Engelbrecht, P., Forlin, C., Eloff, I., \& Swart, E. (2001). Developing a support programme for teachers involved with inclusion in South Africa. International Journal of Special Education, 16, 80-89.

Engelbrecht, P., Oswald, M., Swart, E., \& Eloff, I. (2003). Including learners with intellectual disabilities: Stressful for teachers? International Journal of Disability, Development and Education, 50(3), 293-308.

Frank, J. (1999). Joint initiatives-Education and social services. In B. Norwich (Ed.), Rethinking support for more inclusive schooling. Tamworth: Nasen Publishers.

Garson, P. (2006). Education in South Africa. www.southafrica. info/ess_info/sa_glance/education/education.htm

Gugushe, M. (1999). The needs of a centre-of-learning-based team in implementing the policy of inclusive education. Unpublished M. Ed. dissertation: Rand Academic University.

Hay, J. F., Smit, J., \& Paulsen, M. (2001). Teacher preparedness for inclusive education. Suid Afrikaanse Tydskrif vir Opvoedkunde, 21(4), 213-218.

Hyam, E. M. (2002). The experiences of teachers in developing inclusive classrooms. Unpublished dissertation: Rand Academic University.

Kriel, T. (2001). Ouers se konstruering van hul rolle by insluitende onderwys van ' $n$ leerder met Downsindroom. (Translation: Parents' construction of their roles in inclusive education of their child with Down syndrome). Unpublished dissertation: University of Pretoria.

Lomofsky, L., \& Lazarus, S. (2001). South Africa: first steps in the development of an inclusive education system. Cambridge Journal of Education, 31, 303-317.

Republic of South Africa. (1996). Constitution of the Republic of South Africa, Act 108 of 1996. Pretoria: Government Printers.

Swart, E., Engelbrecht, P., Eloff, I., Oswald, M., \& Pettipher, R. (2004). Developing inclusive school communities: Voices of parents of children with disabilities. Education as Change, 8(1), 80-108.

Swart, E., Engelbrecht, P., Eloff, I., \& Pettipher, R. (2001). Teachers' attitudes towards and experiences in implementing inclusive education in South Africa. Acta Academia, 33(2), August 2001.

UNESCO. (1994). The Salamanca statement and framework for action on special needs education. Adopted by the World Conference on Special Needs Education: Access and quality. Salamanca, Spain: Author. 